\title{
INFLUENCE OF COMPOSITE ELASTIC MODULUS AND LATERAL LOAD PATTERN ON DEFLECTION OF ANTI-SLIDE PILE HEAD
}

\author{
Changdong LI ${ }^{\mathrm{a}}$, Qingtao LIU ${ }^{\mathrm{b}}$, Xinli HU ${ }^{\mathrm{a}}$, Liangqing WANG ${ }^{\mathrm{a}}$, Ez Eldin M. A. M. ${ }^{\mathrm{a}, \mathrm{c}}$ \\ ${ }^{a}$ Faculty of Engineering, China University of Geosciences, 430074, Wuhan, China \\ ${ }^{b}$ Qingdao Geotechnical Investigation And Surveying Institute, 266000, Qingdao, China \\ ${ }^{c}$ Department of Engineering Geology and Hydrogeology, University of Bahri, Khartoum, Sudan
}

Received 28 Sept 2012; accepted 14 May 2013

\begin{abstract}
This paper develops a new method to directly determine the composite elastic modulus of the reinforced concrete cantilever pile rather than adopt theoretical or empirical approaches. On the basis of the theory of material mechanism, the load-deflection equation was deduced to create the relationship between the elastic modulus and the ratio of load-deflection. The numerical modelling tests based on ANSYS separation modelling technology were carried out to determine the composite elastic modulus under different reinforcement ratio, concrete strength grade and distribution pattern of driving force. The results can be used to create the quantitative relationship between the composite elastic modulus and reinforcement ratio as well as concrete strength grade. Comparison amongst various lateral load pattern were made to show that the deflection of pile head is obviously affected by the lateral load pattern, and the corresponding equations of the deflection of the pile head under different lateral load pattern were proposed, which can reflect the ranking of the great influence on the deflection of the pile head, rectangular, trapezoidal and triangular lateral load pattern in order.
\end{abstract}

Keywords: reinforced concrete, cantilever pile, composite elastic modulus, lateral load pattern, deflection.

\section{Introduction}

The push of fast economic construction into mountain regions has led to a tangible increase in occurrence of landslide geohazards. The anti-slide pile without a doubt is the best choice to prevent the landslide. Composite elastic modulus of reinforced concrete and the lateral load pattern are the two crucial factors influencing the deflection of pile head, and their value determination methods have been undertaken by more and more researchers all over the world.

There are numerous empirical equations to predict the modulus of elasticity as a function of compressive strength. Jang et al. (2006) presented an elastic modulus equation to predict the elastic modulus of structural materials made of high and ultra high-strength concrete under the domestic situation in Korea. The performance of adaptive neuro-fuzzy inference system (ANFIS) for predicting the elastic modulus of normal- and high-strength concrete was performed by Aydin et al. (2006). To obtain a practical and universal equation for the modulus of elasticity, multiple regression analyses have been conducted by using a large amount of data, Noguchi et al. (2009) proposed an equation applicable to a wide range of aggregates and admixtures for different concretes. Gupta et al. (2011) carried out the experiments to study the change in direct compressive strength and elastic modulus of recycled aggregate concrete in presence of fly ash.

Also, some researchers focused on the impact of the component and combined environment on the elastic modulus of the concrete. Yang et al. (1996) discussed the impact of moduli of mortar and artificial aggregate on the elastic modulus of concrete. Narayanan and Ramamurthy (2000) summarized the structure characteristic and mechanical properties of aerated concrete. Su et al. (2002) examined the effect of sand ratio on the elastic modulus of self-compacting concrete under various sand ratio condition via slump test, slump flow test, and box test. Khalfallah (2008) proposed a new approach based on the bond stress distribution through the transfer length between the zero-slip and the cracked sections. The effects of high temperature on compressive strength and elastic modulus of high strength concrete were experimentally investigated by Kim et al. (2009). Heirany and Ghaemian (2012) carried out the study on the effect of dam-reservoir-foundation interaction on nonlinear behaviour of concrete gravity dams by a two-dimensional finite element method approach, concerning the physical and mechanics properties of concrete, such as modulus of elasticity, tensile strength and specific fracture energy.

Corresponding author: Liangqing Wang

E-mail:wlq027@126.com 
With respect to the composite elastic modulus of material, several methods are developed to conduct the study of composite elastic modulus and mechanical behaviour of reinforced concrete pile. Chen et al. (2000) and Yu et al. (2008) examined the equivalent modulus of composites by utilizing the micromechanics theoretical method. Tian and Qin (2005) developed a mixed model to investigate the validity of the elastic modulus of composites on the basis of the continuum mechanics theory. Recently, the homogenization method is considered as the popular method to calculate the equivalent properties of macroscopic composites. Hassani and Hinton (1998a, 1998b, 1998c) presented the detailed review and discussion of homogenization and topology optimization. Zhao and Chen (1998) presented the analytical expressions of the effective elastic moduli for concrete under a uniform stress field. Sakaguchi et al. (2004) simulated the elastic modulus and polymerization shrinkage of a light activated polymer matrix composite by using a generalized method of cells (GMC) micromechanics model. Kreja et al. (2005) presented sensitivity analysis of beams and frames assembled of thin-walled members within the adjoint approach. Marfisi and Burgoyne (2007) exposed the micro-structure of concrete with FRP Reinforcement using magnetic resonance imaging technology. However, few studies have been done on the determination methods of composite elastic modulus of reinforced concrete pile under the lateral load. Grabiec (2013) studied the rheological properties of self-compacting concrete mixes containing a viscosity agent (VMA) in their composition. Stehlík (2013) examined the literatures published in the field of application of recycled materials in the building industry to contribute to the enhancement of the existing findings with new experience in using waste admixtures.

In terms of the studies on the pile subjected to the lateral loads, the achievements mainly were obtained by using the field test, model test and numerical modelling methods. Rajashree and Sundaravedivelu (1996) carried out the analysis of laterally loaded piles in soft clay, idealising the pile as beam elements and the soil by nonlinear inelastic spring elements modelled with elasto-plastic sub-elements. Halabe and Jain (1996), Karthigeyan et al. (2006) analysed the single piles under pure lateral loads, and discussed the influence of related parameters. Firat et al. (2006) conducted the lateral load estimation from visco-plastic mud-flow around cylindrical row of piles using principles of applied fluid mechanics. Sližyté (2001a, 2001b) conducted the study on estimation of axially-loaded bored piles interaction in the design of pile foundation, and also examined the interaction estimation of piles bored in sand. Rudžionis and Ivanauskas (2004) presented a study on the influence of thermal-electrical fly ash on the cement paste hydration process. In order to increase the strength of the structural elements under the specific service condition, Bulavs et al. (2005) developed a way of improving the capacity in bending by the use of FRP layers on RC beams with taking into account the non-linear deformation character. Das and Basudhar
(2006) investigated the application of the artificial neural network model to predict the lateral load capacity of piles in clay. Tahghighi and Konagai (2007), Voottipruex et al. (2011) carried out the numerical analysis of nonlinear soil-pile group interaction under lateral loads. Kahyaoğlu et al. (2012) investigated the effects of pile spacing and pile head fixity on the moment and lateral soil pressure distribution along slope stabilizing piles. Sivilevičius et al. (2012) conducted the experimental study on technological indicators of pile-columns at a construction site. Dezi et al. (2012) presented the results of lateral impact load field tests conducted on a near-shore steel pipe pile vibro-driven into soft marine clay.

Amongst limited research works in the field of lateral load acting on piles, the researchers realized that the quality of lateral load distribution in the analysis process has a dramatic effect on estimation of the need to the force and the displacement of systems and structural elements. Bransby and Springman (1999) presented a finite element study to determine the pile-soil-pile interaction behaviour for closely spaced pile rows and groups under passive lateral loading from soil movement. Ozden and Akdag (2009) discussed the modelling considerations, results and analyses of monotonic lateral load tests on SFRC model piles surrounded by a cohesionless soil layer in a testing pool. Etedali and Irandegani (2011) evaluated the nonlinear static analysis of structures under two lateral load patterns, including uniform and triangular lateral load patterns. Khoshnoudian et al. (2011) proposed the lateral load pattern for pushover analysis is given in two forms for symmetric concrete buildings instead of the conventional triangular and uniform load patterns. Nevertheless, the related studies only focused on the uniform and triangular lateral load patterns.

There are several existing methods of presenting the composite elastic modulus and the lateral load acting on piles; unfortunately, few of them are able to take into account the composite elastic modulus of reinforced concrete pile and the distribution pattern of driving force together. This paper aims to propose a new way to study the influence of composite elastic modulus and lateral load pattern on deflection of pile head by utilizing both the analytical and the numerical modelling methods. The study could illustrate and provide some valuable suggestions to determine the composite elastic modulus parameters and the deflection of pile head for the cantilever pile engineering practice.

\section{Relation between elastic modulus and deflection}

In this study, the calculation model of a reinforced concrete cantilever pile applied with a uniformly distributed load can be performed (Fig. 1), where the length of the pile is $\mathrm{h}$ and the uniformly distributed load is $q$. By knowing the value of elastic modulus $(E)$ and the sectional inertia moment $I$, the flexural rigidity of the pile can be determined by multiplying $E$ by $I$. On the basis of this classic mechanical model, the relationship between elastic modulus and deflection can be performed. 
Although there is a linear displacement occurring along the medial axis during the bending of the reinforced concrete cantilever pile, the deflection of the engineering bending component is far less than the length of the pile. Therefore, the linear displacement occurring along the medial axis can be ignored so as to assume that the medial axis should be a flat curve after bending. In the coordinate shown in Figure 1, the relationship between deflection and the medial axis curve can be expressed as follows:

$$
w=f(x),
$$

where: $x$ is the horizontal coordinate of the point before bending deformation; and $w$ is the corresponding deflection.

Based on the theory of material mechanics, the physical relationship between deflection $\mathrm{w}$ and the moment $M$ can be set so as to obtain the deflection curve equation (Eqn (2)) of the pile (Sun et al. 2002):

$$
w^{\prime \prime}=-\frac{M(x)}{E I} .
$$

If the cross section of the pile is the same and the flexural rigidity of the pile $(E I)$ is constant, the mathematical integration on the deflection $w$ will give the following equation:

$$
E I \cdot w=-\int\left[\int M(x) d x\right] d x .
$$

On the basis of the mechanical model of the cantilever pile with the uniformly distributed load shown in Figure 1, we can establish the relationship between the moment $M$ and the uniformly distributed load $q$ can be established as follows:

$$
M(x)=-\frac{1}{2} q x^{2}+q h x-\frac{1}{2} q h^{2},
$$

where $h$ is the length of the pile.

The deflection solution $w$ can be obtained by a system of equations (Eqns (3) and (4)):

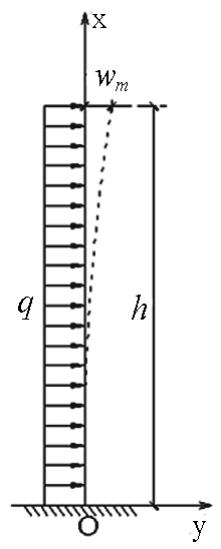

Fig. 1. Mechanical model of cantilever pile with uniformly distributed load

$$
w=\frac{q x^{2}}{24 E I}\left(x^{2}+6 h^{2}-4 h x\right)
$$

Due to the uniformly distributed load of the rectangular pattern, the total force acting on the pile $F$ is equal to $q$ multiplied $h$, i.e. $F=q h$.

The maximum deflection occurs at the end of the pile, i.e. $x=h$, where the maximum deflection $W_{r m}$ can be obtained:

$$
w_{r m}=\frac{q h^{4}}{8 E I}=\frac{F h^{3}}{8 E I} .
$$

Then, the elastic modulus $E$ can be expressed as:

$$
E=\frac{q h^{4}}{8 I \cdot w_{r m}}=\frac{h^{4}}{8 I} \cdot \frac{q}{w_{r m}} .
$$

Eqn (7) shows that the relationship between the elastic modulus and the deflection is inversely proportional, i.e. the smaller is the elastic modulus, the larger is the deflection, and vice versa. Moreover, $h$ and $I$ are the constant values; therefore, the key problem to determine the elastic modulus is the ratio between the uniformly distributed load and deflection $\left(q / w_{r m}\right)$. Under the condition of the maximum deflection, the minimum elastic modulus of the composites can be used as the design parameters for the engineering practice.

\section{Composite elastic modulus of reinforced concrete cantilever pile}

\subsection{Calibration test of composite elastic modulus}

Figure 2 shows the cross-section dimension of the reinforced concrete cantilever pile and the load (the strength grade of concrete is $\mathrm{C} 20$ ). With respect to the concrete C20, the Young's Modulus is $2.55 \times 10^{4} \mathrm{MPa}$ and the Poisson's ratio is 0.30 . Under the first computational case, $q=3.6 \mathrm{~N} / \mathrm{mm}$, the deformation of the bending curve of the cantilever pile under the case of no steel bars (Fig. 3) can be obtained by using the ANSYS software.

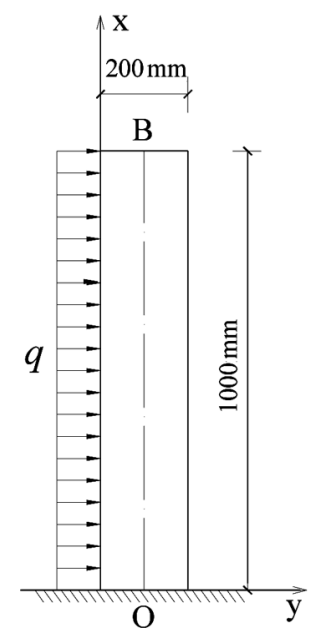

Fig. 2. Size of cantilever pile under the action of uniformly dstributed load 


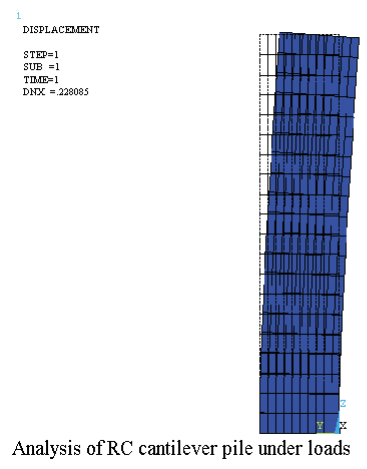

Fig. 3. Bending deformation of cantilever pile without steel bars under uniformly distributed load with a collection degree of $3.6 \mathrm{~N} / \mathrm{mm}$

Under this case, the computational result shows that the maximum deflection $w_{r m}$ is $0.228085 \mathrm{~mm}$ at the point of $\mathrm{B}$; therefore, it can be represented by $w_{B}$, which can be used in Eqn (7) to calculate the elastic modulus, and then we can arrive $E_{\mathrm{c}}=2.47 \times 10^{4} \mathrm{MPa}$. Comparing the calculated result with the real elastic modulus of the cantilever pile $\left(E_{\mathrm{c}}=2.55 \times 10^{4} \mathrm{MPa}\right)$, the difference is quite small, only $3.1 \%$. The computed result can be accepted because it lies within the allowable range. The above calibration test proves the accuracy of the numerical modelling method to calculate the composite elastic modulus is feasible.

\subsection{Solution for composite elastic modulus of pile}

With reference to the case of the steel bar inside the concrete, tension and stirrup reinforcements are inside the reinforced concrete cantilever pile, whose detailed arrangement is presented in Figure 4. The corresponding computational model can be performed with the 4 tension steel bars, 2 auxiliary steel bars and stirrup reinforcement (Figs 2 and 4). The Poisson's ratio of the steel bar is 0.3 . Table 1 shows the detailed parameters of the steel bars.

The separation modelling technology is used to conduct the numerical modelling. SOLID65 element is selected for the concrete modelling, and the LINK8 element is adopted for the steel bars. This way of modelling method deals with the microstructure property of the reinforced concrete cantilever pile.

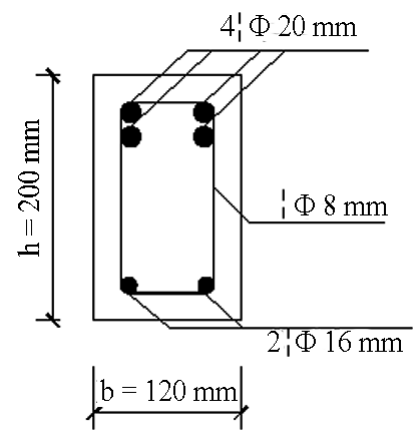

Fig. 4. Cross sectional dimensions of reinforced concrete cantilever pile
Table 1. Mechanical parameters of different steel bars

\begin{tabular}{lcc}
\hline Kind of steel bars & $\begin{array}{c}\text { Diameter } \\
(\mathrm{mm})\end{array}$ & $\begin{array}{c}\text { Elastic modulus } \\
(\mathrm{MPa})\end{array}$ \\
\hline Tension steel bars & 20 & $2.0 \times 10^{5}$ \\
\hline Auxiliary steel bars & 16 & $2.0 \times 10^{5}$ \\
\hline Stirrup reinforcement & 8 & $2.1 \times 10^{5}$ \\
\hline
\end{tabular}

Under different cases, the deflection of the reinforced concrete cantilever pile can be calculated by using the ANSYS software (Table 2). The displacement contour graph of $\mathrm{Y}$ direction under $q=12 \mathrm{~N} / \mathrm{mm}$ is presented in Figure 5, where the maximum deflection $=0.579427 \mathrm{~mm}$. The relationship between the load and deflection indicates the good quality linear relationship (Fig. 6).

The corresponding relationship equation of $q$ and $w_{B}$ can be obtained by using the curve fitting (Eqn (8)), with the correlation coefficient square of 0.9940 , where the slope of the linear curve is $q / w_{B}=19.858$ :

$$
q=19.858 w_{B} .
$$

Using Eqn (7), and the value of $q / w_{B}=19.858$, the composite elastic modulus of the reinforced concrete cantilever pile can be obtained, i.e. $E_{c e}=3.1 \times 10^{4} \mathrm{MPa}$, which is larger than that of the plain concrete. The reason is that

Table 2. Pile head deflection obtained by numerical simulation under different loads

\begin{tabular}{cccc}
\hline No. & $\begin{array}{c}\text { Collection degree of load } \\
(\mathrm{N} / \mathrm{mm})\end{array}$ & $\begin{array}{c}\text { Stress } \\
(\mathrm{MPa})\end{array}$ & $\begin{array}{c}\text { Deflection } \\
(\mathrm{mm})\end{array}$ \\
\hline 1 & 0.0 & 0.00 & 0.000000 \\
\hline 2 & 2.4 & 0.02 & 0.092562 \\
\hline 3 & 4.8 & 0.04 & 0.185124 \\
\hline 4 & 7.2 & 0.06 & 0.301480 \\
\hline 5 & 9.6 & 0.08 & 0.417984 \\
\hline 6 & 12.0 & 0.10 & 0.579427 \\
\hline 7 & 14.4 & 0.12 & 0.724165 \\
\hline 8 & 16.8 & 0.14 & 0.873573 \\
\hline 9 & 19.2 & 0.16 & 1.016000 \\
\hline
\end{tabular}

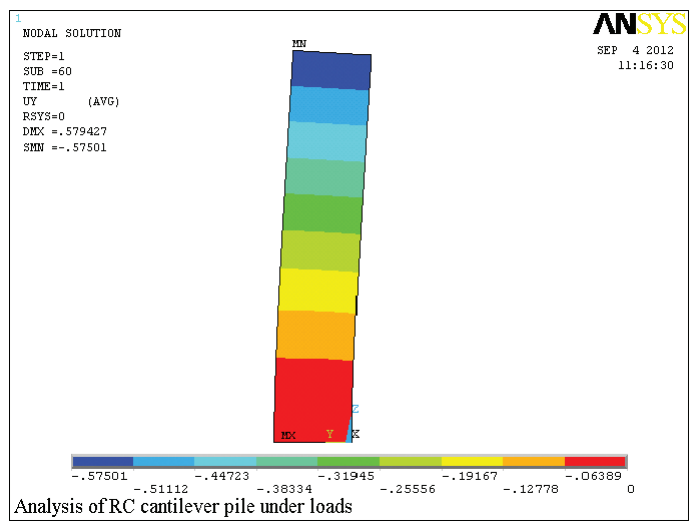

Fig. 5. Y-direction displacement contour of cantilever pile with steel bars under uniformly distributed with a collection degree load of $12 \mathrm{~N} / \mathrm{mm}$ 


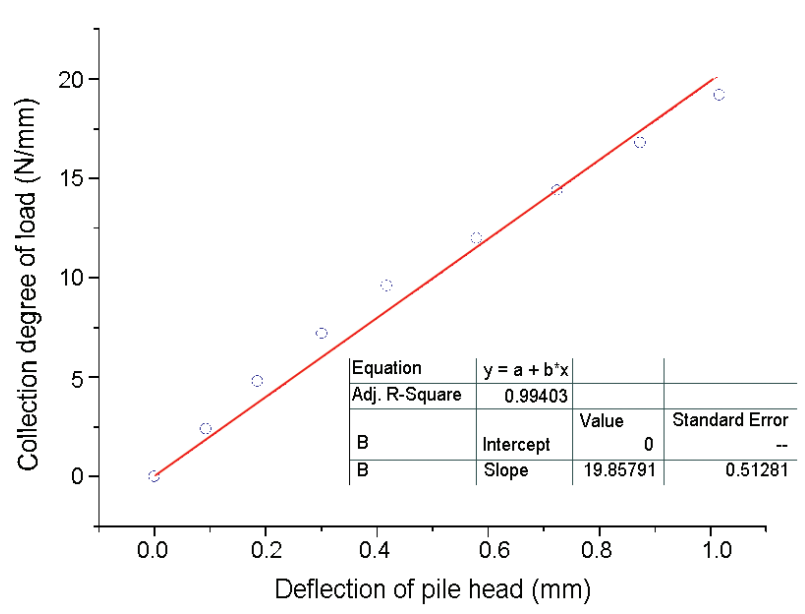

Fig. 6. Fitting relationship curve between collection degree of loads and deflection of pile head

the composite elastic modulus of reinforced concrete depends on the reinforcement ratio of steel bars and the concrete strength grade. Therefore, the influence of reinforcement ratio and concrete strength grade acting on the composite elastic modulus should be discussed in details in the following sections.

\subsection{Influence of reinforcement ratio on composite elastic modulus}

In order to examine the influence of reinforcement ratio on composite elastic modulus, we assume that the grade of the concrete is kept constant, i.e. C25. The reinforcement ratio varies from 0.0424 to 0.1340 with the diameter of the steel bar varies from $18 \mathrm{~mm}$ to $32 \mathrm{~mm}$ under a collection degree load of $12 \mathrm{~N} / \mathrm{mm}$. The corresponding deflection (pile head) and composite elastic modulus under different reinforcement ratio are listed in Table 3.

The composite elastic modulus increases with the increase of the reinforcement ratio (Fig. 7). Furthermore, the relationship can be expressed by a Polynomial function (Eqn (9)) with the correlation coefficient square of 0.9944, which shows that the high fitting precision of the fitting equation:

$$
E_{c e}=157805.012 \rho+27988.035,
$$

where: $\rho$ is the reinforcement ratio; and $E_{c e}$ is the composite elastic modulus (MPa).

Table 3. Deflection and composite elastic modulus with concrete strength grade $\mathrm{C} 25$ under different reinforcement ratio

\begin{tabular}{cccc}
\hline $\begin{array}{c}\text { Diameter of } \\
\text { steel bar } \\
(\mathrm{mm})\end{array}$ & $\begin{array}{c}\text { Reinforcement } \\
\text { ratio }\end{array}$ & $\begin{array}{c}\text { Deflection } \\
(\mathrm{mm})\end{array}$ & $\begin{array}{c}\text { Composite } \\
\text { modulus } \\
(\mathrm{MPa})\end{array}$ \\
\hline 18 & 0.0424 & 0.64 & 29300 \\
\hline 20 & 0.0524 & 0.56 & 33300 \\
\hline 22 & 0.0634 & 0.50 & 37200 \\
\hline 25 & 0.0819 & 0.45 & 41300 \\
\hline 28 & 0.1026 & 0.40 & 46700 \\
\hline 32 & 0.1340 & 0.37 & 50200 \\
\hline
\end{tabular}

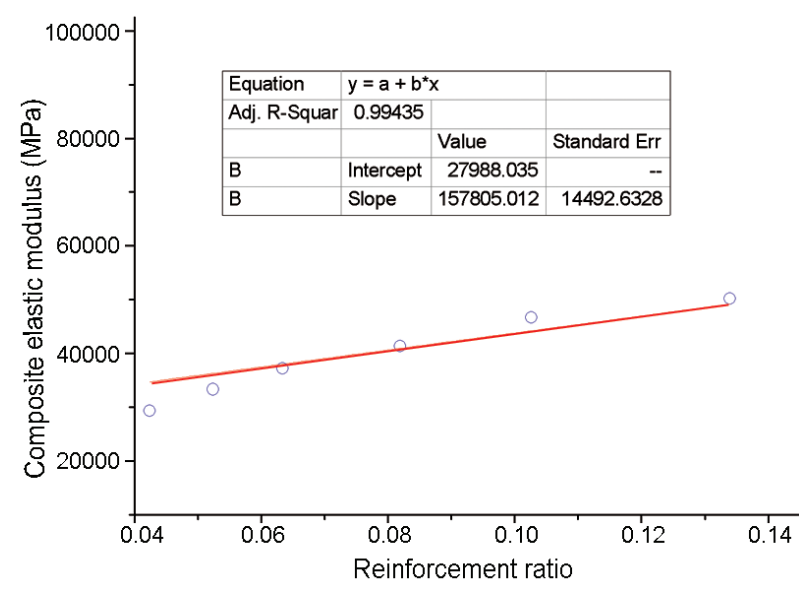

Fig. 7. Fitting relationship curve between composite elastic modulus and reinforcement ratio

Under the condition of reinforcement ratio $\rho$ is equal to 0 , i.e. plain concrete; the corresponding composite elastic modulus is $27988.035 \mathrm{MPa}$, which is quite close to the actual elastic modulus of plain concrete with strength grade C25, namely $28000 \mathrm{MPa}$.

\subsection{Influence of concrete strength on the composite elastic modulus}

It is possible to study the influence of concrete strength grade on composite elastic modulus under the case of constant reinforcement (the steel bar diameter is $20 \mathrm{~mm}$ ), while the concrete strength grade varies from $\mathrm{C} 20$ to C55 (Table 4).

With reference to Figure 8, the following conclusions can be drawn: (1) the higher is the concrete strength grade, the greater is the composite elastic modulus; (2) the relationship between the composite elastic modulus and the concrete strength grade is well fitted by linear function curve, with the correlation coefficient square of 0.9721 , which can be expressed by the following equation (Eqn (10)):

$$
E_{c e}=0.353 \cdot E_{c}+23442.691,
$$

where: $E_{c}$ is the elastic modulus of concrete.

Table 4. Deflection and composite elastic modulus under different concrete strength grade

\begin{tabular}{lcccc}
\hline $\begin{array}{l}\text { Strength } \\
\text { grade of } \\
\text { concrete }\end{array}$ & $\begin{array}{c}\text { Elastic } \\
\text { modulus } \\
(\mathrm{MPa})\end{array}$ & $\begin{array}{c}\text { Load } \\
(\mathrm{N} / \mathrm{m}=\mathrm{m})\end{array}$ & $\begin{array}{c}\text { Deflection } \\
(\mathrm{mm})\end{array}$ & $\begin{array}{c}\text { Composite } \\
\text { elastic modulus } \\
(\mathrm{MPa})\end{array}$ \\
\hline C20 & 25500 & 12 & 0.576118 & 32550 \\
\hline C25 & 28000 & 12 & 0.562843 & 33310 \\
\hline C30 & 30000 & 12 & 0.551320 & 34010 \\
\hline C35 & 31500 & 12 & 0.545646 & 34360 \\
\hline C40 & 32500 & 12 & 0.541902 & 34600 \\
\hline C45 & 33500 & 12 & 0.530189 & 35360 \\
\hline C50 & 34500 & 12 & 0.522042 & 35910 \\
\hline C55 & 35500 & 12 & 0.521965 & 35920 \\
\hline
\end{tabular}




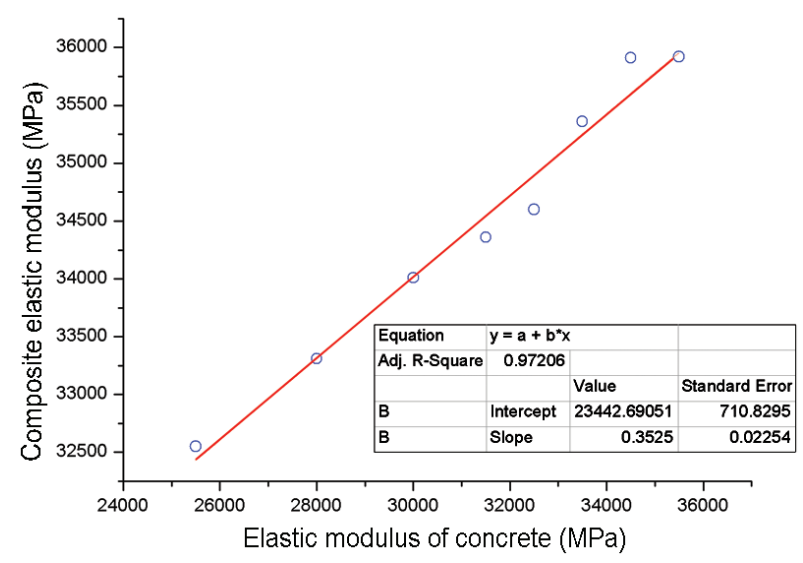

Fig. 8. Fitting relationship curve between composite elastic modulus and elastic modulus of concrete

The comparison between the above two fitting equations (Eqns (9) and (10)) indicates that the overall increasing trend of the composite elastic modulus is the same. However, the coefficient of Eqn (9) is much greater than that of Eqn (10), it means that the contribution of the steel bar is much larger than that of the concrete, i.e. the reinforcement ratio of the steel bar is the crucial role influenced the composite elastic modulus of the pile.

\section{Influence of lateral load pattern on deflection of pile head}

The landslide is considered as a lateral distribution load on the pile. However, the distribution form of the driving force is not always represented as the rectangular uniform distribution. As a result, besides the rectangular distribution form of driving force, the more universal distribution form, such as triangular distribution and trapezoidal distribution, should also be seriously examined.

\subsection{Triangular distribution function of lateral load}

We suppose that the height of the pile is $h$ (Fig. 9), and the total driving force of landslide is $F$; then we can gain the expression of the stress distribution is:

$$
q=\frac{2 F}{h} \text {. }
$$

The deflection curve equation of the triangular distribution function of force can be deduced by the similar approach of rectangular distribution form presented above, and it can be expressed as follows:

$$
\omega_{t}=\frac{q z^{2}}{120 E I h}\left(10 h^{3}-10 h^{2} z+5 h z^{2}-z^{3}\right) .
$$

At the tip point of the pile, when $x$ reaches to the head of the pile, i.e. $x=h$, the deflection of the pile head can be expressed as follows:

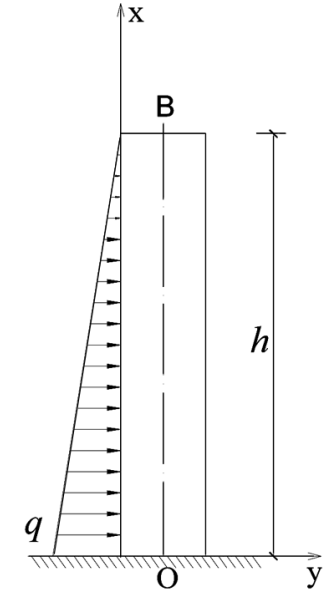

Fig. 9. Mechanical model of cantilever pile with triangular distribution load

$$
\omega_{t m}=\frac{q h^{4}}{30 E I}
$$

Substitute Eqn (11) into Eqn (13), the relation equation between the driving force and the deflection can be obtained:

$$
\omega_{t m}=\frac{F h^{4}}{15 E I}
$$

\subsection{Trapezoidal distribution function of lateral load}

Under the case of trapezoidal distribution function, a similar analysis of load distribution can be performed. We can gain the expression of the total driving force:

$$
F=q h-\frac{1}{2} \times h^{2} \cot \alpha,
$$

where: $\alpha$ is the slope angle of the driving force (Fig. 10).

This yields expressions relating $q$ and $F$ :

$$
q=\frac{F}{h}+\frac{h}{2} \cot \alpha .
$$

Figure 10 illustrates that the trapezoidal distribution can be divided into two parts, one is the triangular distribution part, and the other is the rectangular distribution part. On the basis of the superposition principle of material mechanics, the deflection of the pile under trapezoidal distribution condition can be obtained by the sum of that by the triangular distribution part and the rectangular distribution parts.

Thereby, the total deflection under the trapezoidal distribution can be expressed as follows:

$$
w_{t p m}=w_{r m}+w_{t m}
$$

where: $w_{r m}$ is the deflection of the pile head under the rectangular distribution (Eqn (6)), while $w_{t m}$ is the 


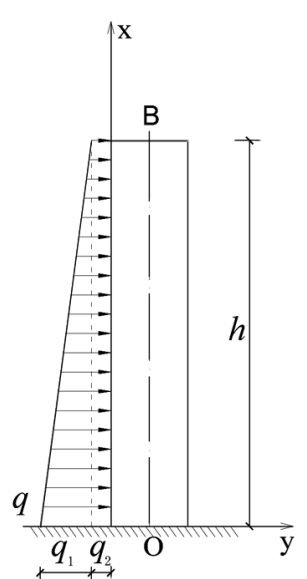

Fig. 10. Mechanical model of cantilever pile with trapezoidal distribution load

deflection of the pile head under the triangular distribution (Eqn (13)).

Substituting Eqns (6) and (13) into Eqn (17), we can then get the expression of $w_{t p m}$ :

$$
w_{t p m}=\frac{q_{1} h^{4}}{30 E I}+\frac{q_{2} h^{4}}{8 E I}=\frac{\cot \alpha \cdot h^{5}}{30 E I}+\frac{q_{2} h^{4}}{8 E I},
$$

where: $q_{1}, q_{2}$ and $q$ are the maximum load intensities of the triangular, rectangular and trapezoidal distributions, respectively.

Figure 10 shows that geometrical relationship between $q_{2}$ and $q$, which can be expressed as follows:

$$
q_{2}=q-h \cot \alpha
$$

Substituting Eqn (16) into Eqn (19), we can arrive to the relationship between $F$ and $q_{2}$ :

$$
q_{2}=\frac{F}{h}-\frac{h}{2} \cot \alpha
$$

Then, substituting Eqn (20) into Eqn (18), we can finally obtain the expression of the deflection of the pile head under the trapezoidal distribution load:

$$
w_{t p m}=\frac{\cot \alpha \cdot h^{5}}{30 E I}+\frac{h^{4}\left(\frac{F}{h}-\frac{h}{2} \cot \alpha\right)}{8 E I}=\frac{F h^{3}}{8 E I}-\frac{7 h^{5} \cot \alpha}{240 E I} .
$$

\subsection{Comparison and analysis}

Comparison amongst the above three kinds of load distribution, including rectangular (Eqn (6)), triangular (Eqn (14)) and trapezoidal (Eqn (21)) distribution, shows that the deflection of pile head is obviously affected by the load distribution pattern, which can reflect the ranking of the great influence on the deflection of the pile head, rectangular, trapezoidal and triangular lateral load pattern in order. It is clear to find that the deflection of the pile head under the rectangular load pattern is always the largest.
Correspondingly, the deflection of the pile head under the triangular is only $53.33 \%$ of that under the rectangular load pattern. Therefore, in order to calculate the deflection of the pile head, it is crucial to investigate the lateral load pattern of driving force at first.

\section{Discussion}

During the engineering practice, the elastic modulus of the reinforced concrete has been always replaced by the elastic modulus of concrete due to the conservation design purpose. However, the study in this paper points out that the composite elastic modulus which affected by the reinforcement ratio and concrete strength grade should not be ignored. Also, this paper presents a quantitative way of determining the composite elastic modulus of reinforced concrete pile.

The comparison and analysis presented above show that different lateral load pattern would induce different deflection of pile head. However, in the practice of landslides engineering, it is always difficult to determine the load distribution pattern of the driving force, while the deflection of pile head can be obtained easily. Therefore, it is possible to carry out a back-analysis to conduct the study on load distribution pattern of driving force via the displacement of the pile head.

\section{Conclusions}

This paper developed a separation modelling technology to conduct the numerical modelling of reinforcement pile, which can reflect the microstructure property of the reinforced concrete cantilever pile. A calibration test is used as a case study to prove the accuracy of the numerical modelling method applied to the pile of composite elastic modulus. The results showed that the difference is only $3.3 \%$, which can be accepted within the allowable range, it proved the high accuracy of the numerical modelling method. The above calibration test proves the accuracy of the numerical modelling method to calculate the composite elastic modulus is feasible.

Based on the basic theory of the material mechanism, the load-deflection equation can be performed to develop a way of determining the composite elastic modulus of the reinforcement pile by using the finite element method. The numerical modelling result shows that the composite elastic modulus of the reinforcement pile increases with the increasing of the reinforcement ratio and concrete strength grade. Furthermore, the reinforcement ratio of steel bar is the crucial role due to its great contribution to the whole.

Comparison amongst various lateral load pattern were made to show that the deflection of pile head is obviously affected by the lateral load pattern, and the corresponding equations of the deflection of the pile head under different lateral load pattern were proposed, which can reflect the ranking of the great influence on the deflection of the pile head, rectangular, trapezoidal and triangular lateral load pattern in order. 
It is crucial to investigate the distribution load pattern at first so as to calculate the deflection of the pile head. On the whole, the deflection under the triangular distribution load is the smallest, and the deflection under the rectangular distribution load is the largest. With the change of the inclination angle of load distribution, the deflection under the trapezoidal distribution load is intervenient among the above two limits. Furthermore, the above analysis related to the deflection and load distribution pattern would be used to perform a back-analysis problem, which is of great importance to the structure design of anti-slide piles.

\section{Acknowledgements}

The work was funded by National Natural Science Foundation of China (Nos. 41202198, 41372310 and 41472261), the Special Fund for Basic Scientific Research of Central Colleges, China University of Geosciences (Wuhan) (CUG130409 and CUG090104), National Basic Research Program of China (973 Program) (No. 2011CB710604). The authors would like to extend their most sincere gratitude to the friends who provided help during the writing of this paper.

\section{References:}

Aydin, A. C.; Tortum, A.; Yavuz, M. 2006. Prediction of concrete elastic modulus using adaptive neuro-fuzzy inference system, Civil Engineering and Environmental Systems 23(4): 295-309. http://dx.doi.org/10.1080/10286600600772348

Bransby, M. F.; Springman, S. 1999. Selection of load-transfer functions for passive lateral loading of pile groups, Computers and Geotechnics 24(3): 155-184. http://dx.doi.org/10.1016/S0266-352X(99)00006-3

Bulavs, F.; Radinsh, I.; Tirans, N. 2005. Improvement of capacity in bending by the use of FRP layers on RC beams, Journal of Civil Engineering and Management 11(3): 169-174. http://dx.doi.org/10.1080/13923730.2005.9636347

Chen, Z. R.; Zhu, D. C.; Lu, M. 2000. Effective elastic properties of composites, Acta Materiae Compositae Sinica 17(3): 73-77.

Das, S. K.; Basudhar, P. K. 2006. Undrained lateral load capacity of piles in clay using artificial neural network, Computers and Geotechnics 33(8): 454-459. http://dx.doi.org/10.1016/j.compgeo.2006.08.006

Dezi, F.; Gara, F.; Roia, D. 2012. Dynamic response of a nearshore pile to lateral impact load, Soil Dynamics and Earthquake Engineering 40: 34-47. http://dx.doi.org/10.1016/j.soildyn.2012.04.002

Etedali, S.; Irandegani, M. A. 2011. A new proposal of lateral load pattern for nonlinear static analysis of structures, International Journal of Advanced Engineering Sciences and Technologies 5(2): 201-208.

Firat, S.; Sarıbıyık, M.; Celebi, E. 2006. Lateral load estimation from visco-plastic mud-flow around cylindrical row of piles, Applied Mathematics and Computation 173(2): 803-821. http://dx.doi.org/10.1016/j.amc.2005.04.016

Grabiec, A. M. 2013. Influence of viscosity modifying agent on some rheological properties, segregation resistance and compressive strength of self-compacting concrete, Journal of Civil Engineering and Management 19(1): 1-8. http://dx.doi.org/10.3846/13923730.2012.737830
Gupta, A.; Mandal, S.; Ghosh, S. 2011. Direct compressive strength and Elastic modulus of recycled aggregate concrete, International Journal of Civil and Structural Engineering 2(1): 292-304.

Halabe, U. B.; Jain, S. K. 1996. Lateral free vibration of a single pile with or without an axial load, Journal of Sound and Vibration 195(3): 420-433.

http://dx.doi.org/10.1006/jsvi.1996.0443

Hassani, B.; Hinton, E. 1998a. A review of homogenization and topology optimization I - homogenization theory for media with periodic structure, Computers and Structures 69(6): 707-717.

Hassani, B.; Hinton, E. 1998b. A review of homogenization and topology optimization II - analytical and numerical solution of homogenization equations, Computers and Structures 69(6): 719-738.

Hassani, B.; Hinton, E. 1998c. A review of homogenization and topology optimization III-topology optimization using optimality criteria, Computers and Structures 69(6): 739-756.

Heirany, Z.; Ghaemian, M. 2012. The effect of foundation's modulus of elasticity on concrete gravity dam's behaviour, Indian Journal of Science and Technology 5(5): 2738-2740.

Jang, I. Y.; Park, H. K.; Yoon, Y. S. 2006. A proposal of an elastic modulus equation for high-strength and ultra high-strength concrete, International Journal of Concrete Structures and Materials 18(1E): 43-48. http://dx.doi.org/10.4334/IJCSM.2006.18.1E.043

Kahyaoğlu, M. R.; Onal, O.; Imançl, G.; Ozden, G.; Kayalar, A. Ș. 2012. Soil arching and load transfer mechanism for slope stabilized with piles, Journal of Civil Engineering and Management 18(5): 701-708. http://dx.doi.org/10.3846/13923730.2012.723353

Karthigeyan, S.; Ramakrishna, V. V. G. S. T.; Rajagopal, K. 2006. Influence of vertical load on the lateral response of piles in sand, Computers and Geotechnics 33(2): 121131. http://dx.doi.org/10.1016/j.compgeo.2005.12.002

Khalfallah, S. 2008. Tension stiffening bond modelling of cracked flexural reinforced concrete beams, Journal of Civil Engineering and Management 14(2): 131-137. http://dx.doi.org/10.3846/1392-3730.2008.14.8

Khoshnoudian, F.; Mestri, S.; Abedinik, F. 2011. Proposal of lateral load pattern for pushover analysis of RC buildings, Computer Methods in Civil Engineering 2(2): 169-183.

Kim, G. Y.; Kim, Y. S.; Lee, T. G. 2009. Mechanical properties of high-strength concrete subjected to high temperature by stressed test, Transactions of Nonferrous Metals Society of China 19(z1): 128-133. http://dx.doi.org/10.1016/S1003-6326(10)60260-9

Kreja, I.; Mikulski, T.; Szymczak, C. 2005. Adjoint approach sensitivity analysis of thin-walled beams and frames, Journal of Civil Engineering and Management 11(1): 57-64.

Marfisi, E.; Burgoyne, C. J. 2007. Magnetic resonance imaging of concrete with FRP Reinforcement, in $8^{\text {th }}$ International Symposium on Fiber Reinforced Polymer Reinforcement for Concrete Structures (FRPRCS-8), 16-18 July 2007, Patras, Greece, 1-10.

Narayanan, N.; Ramamurthy, K. 2000. Structure and properties of aerated concrete: a review, Cement \& Concrete Composites 22(5): 321-329. http://dx.doi.org/10.1016/S0958-9465(00)00016-0

Noguchi, T.; Tomosawa, F.; Nemati, K. M.; Chiaia, B. M.; Fantilli, A. P. 2009. A practical quation for elastic modulus of concrete, ACI Structural Journal 106(5): 690-696.

Ozden, G.; Akdag, C. T. 2009. Lateral load response of steel fiber reinforced concrete model piles in cohesionless soil, Construction and Building Materials 23(2): 785-794. http://dx.doi.org/10.1016/j.conbuildmat.2008.03.001 
Rajashree, S. S.; Sundaravedivelu, R. 1996. Degradation model for one-way cyclic lateral load on piles in soft clay, Computers and Geotechnics 19(4): 289-300. http://dx.doi.org/10.1016/S0266-352X(96)00008-0

Rudžionis, Ž.; Ivanauskas, E. 2004. Investigations into effective fly ash used in concrete, Journal of Civil Engineering and Management 10(4): 303-309. http://dx.doi.org/10.1080/13923730.2004.9636323

Sakaguchi, R. L.; Wiltbank, B. D.; Murchison, C. F. 2004. Prediction of composite elastic modulus and polymerization shrinkage by computational micromechanics, Dental Materials 20(4): 397-401. http://dx.doi.org/10.1016/j.dental.2003.11.003

Sivilevičius, H.; Daniūnas, A.; Zavadskas, E. K.; Turskis, Z.; Sušinskas, S. 2012. Experimental study on technological indicators of pile-columns at a construction site, Journal of Civil Engineering and Management 18(4): 512-518. http://dx.doi.org/10.3846/13923730.2012.709958

Sližyte, D. 2001a. Estimation of axially-loaded bored piles interaction in the design of pile oundation, Statyba - Civil Engineering 7(3): 201-206.

Sližyte, D. 2001b. The interaction estimation of piles bored in sand, Statyba - Civil Engineering 7(5): 405-412.

Stehlík, M. 2013. Testing the strength of concrete made from raw and dispersion-treated concrete recyclate by addition of additives and admixtures, Journal of Civil Engineering and Management 19(1): 107-112.

http://dx.doi.org/10.3846/13923730.2012.734853
Su, J. K.; Cho, S. W.; Yang, C. C.; Huang, R. 2002. Effect of sand ratio on the elastic Modulus of self-compacting concrete, Journal of Marine Science and Technology 10(1): 8-13.

Sun, X. F.; Fang, X. S.; Guan, L. T. 2002. Material mechanics. $4^{\text {th }}$ ed. Beijing: Higher Education Press. 387 p.

Tahghighi, H.; Konagai, K. 2007. Numerical analysis of nonlinear soil-pile group interaction under lateral loads, Soil Dynamics and Earthquake Engineering 27(5): 463-474. http://dx.doi.org/10.1016/j.soildyn.2006.09.005

Tian, Y. D.; Qin, S. L. 2005. Improved mixed model method of valid elastic modulus of composites, Journal of Southwest Jiaotong University 40(6): 783-787.

Voottipruex, P.; Suksawat, T.; Bergado, D. T.; Jamsawang, P. 2011. Numerical simulations and parametric study of SDCM and DCM piles under full scale axial and lateral loads, Computers and Geotechnics 38(3): 318-329. http://dx.doi.org/10.1016/j.compgeo.2010.11.006

Yang, C. C.; Lin, Y. Y.; Huang, R. 1996. Elastic modulus of concrete affected by elastic moduli of mortar and artificial aggregate, Journal of Marine Science and Technology 4(1): 43-48.

Yu, J. H.; He, G. X.; Zhang, F.; Huang, C. K. 2008. solution method of meso-mechanics to elastic moduli of fiber reinforced concrete, Journal of Architecture and Civil Engineering 25(2): 101-105.

Zhao, X. H.; Chen, W. F. 1998. The effective elastic moduli of concrete and composite materials, Composites Part B: Engineering 29(1): 31-40. http://dx.doi.org/10.1016/S1359-8368(97)80861-X

Changdong LI. PhD, Associate Professor in the Department of Engineering Geology and Geotechnique, Faculty of Engineering, China University of Geosciences, Wuhan, China. His research interest is the interaction mechanism between the engineering structure and geological mass, especially the mechanical behaviour and deformation of concrete piles.

Qingtao LIU. Assistant Engineer, in the Research Institute of Geotechnical Investigation, Qingdao Geotechnical Investigation And Surveying Institute, Qingdao, China, Wuhan, China. His research interest is the mechanical behaviour and deformation of engineering structure by different approaches, including theory analysis and numerical modelling methods.

Xinli HU. PhD, Professor in the Department of Engineering Geology and Geotechnique, Vice dean of Faculty of Engineering, China University of Geosciences, Wuhan, China. Her research interest is anti-sliding effect of the engineering structure.

Liangqing WANG. PhD, Professor, Head of the Engineering Geology and Geotechnique, Faculty of Engineering, China University of Geosciences, Wuhan, China. His research interest is the control of geo-hazards with engineering structure, particularly the mechanical analysis on concrete piles.

Ez Eldin M. A. M. Researcher at the Department of Engineering Geology and Geotechnique, Faculty of Engineering, China University of Geosciences, Wuhan, China and Head Department of Engineering Geology and Hydrogeology, University of Bahri, Khartoum, Sudan. His research interest is the site investigation and evaluation of geological and geoengineering properties of soil and rock materials and application of geophysics in the fields of civil engineering and geotechnical engineering. 